Section Editors

David C. Spencer, MD

Steven Karceski, MD

Robert J. Fox, MD, FAAN

\title{
Complementary and alternative medicine in multiple sclerosis
}

WHAT IS COMPLEMENTARY AND ALTERNATIVE MEDICINE? Although it is sometimes hard to define, complementary and alternative medicine (CAM) refers to health care approaches that are developed outside of mainstream and conventional medicine. ${ }^{1}$ "Complementary" and "alternative" are often used interchangeably, but there are some differences. "Complementary medicine" generally refers to using a nonmainstream approach together with conventional medicine. "Alternative medicine" refers to using a nonmainstream approach in place of conventional medicine. The boundaries between complementary and conventional medicine can overlap and even change with time. Most CAM therapies are not regulated by the US Food and Drug Administration, which means the quality and purity of CAM therapies may vary significantly.

WHY WERE EVIDENCED-BASED GUIDELINES DEVELOPED FOR CAM THERAPIES IN MULTIPLE SCLEROSIS? Although there are treatments for the early stages of multiple sclerosis (MS), there is currently no known cure for MS. People are often left with uncomfortable symptoms that can be difficult to manage. Therefore, some people look to CAM therapies to treat MS and its symptoms. CAM use is common in MS: up to $80 \%$ of people with MS report use of CAM therapy. With such widespread use, it is helpful for clinicians to understand the evidence supporting various CAM therapies in MS.
WHAT DID THE AMERICAN ACADEMY OF NEUROLOGY EXPERTS FIND ABOUT CAM TREATMENTS IN MS? As summarized in table 1, the American Academy of Neurology panel found evidence to support the effectiveness of cannabinoids against some MS symptoms. ${ }^{2}$ Cannabinoids are a group of chemicals related to the active ingredient in cannabis (marijuana). They also found that ginkgo biloba, reflexology, and magnetic therapy may be effective against some MS symptoms. They found several therapies to be either possibly or probably ineffective for treating MS disease activity and a variety of MS symptoms. Perhaps just as importantly, 22 therapies had insufficient evidence to determine whether they were effective or ineffective (table 2).

WHAT DOES THIS MEAN FOR PEOPLE WITH MS? People with chronic diseases like MS, which has no cure, are often attracted to CAM therapies to treat the disease or relieve symptoms. CAM treatments can include pills, liquids, diets, and exerciseseven invasive surgical procedures. Some approaches may have little potential for harm, but others may have side effects, significant risks, steep financial costs, or dangerous interactions with conventional medications. For example, people using cannabis to relieve MS symptoms should talk to their clinician about possible side effects such as dizziness, thinking problems, and psychological problems such as depression. It is important for people to let their clinicians

Table 1 Complementary and alternative medicine (CAM) therapies with sufficient evidence to support practice recommendations in multiple sclerosis

\section{CAM intervention}

Cannabinoids (cannabis and related compounds:

Ginkgo biloba

Cari Loder regimen (lofepramine plus phenylanine with vitamin $B_{12}$ )

Reflexology

Bee venom

Magnetic therapy

Probably effective against fatigue

Evidence supporting benefit

Possibly effective against fatigue sensation)
Established as effective or probably effective against symptoms of spasticity and pain from spasticity

Possibly effective in helping paresthesia (pins-and-needles

Adapted from Yadev et al. ${ }^{2}$
Evidence supporting no benefit

Probably ineffective against tremor

Established as ineffective in helping cognitive function Possibly ineffective against MS disability, depression, and fatigue

Possibly ineffective against relapses, MS disability, MRI lesions, fatigue, and health-related quality of life

Probably ineffective against depression

Probably ineffective against relapses, disability, MRI lesions, fatigue, and health-related quality of life 


\begin{tabular}{|ll|}
\hline Table 2 & $\begin{array}{c}\text { Complementary and alternative medicine (CAM) interventions with } \\
\text { insufficient evidence to support a specific practice recommendation }\end{array}$ \\
Category of CAM intervention & Specific CAM intervention \\
Mind-body medicine & Biofeedback \\
& Music therapy \\
& Mindfulness-based training \\
Biologically based practices & Hypnosis \\
& Padma 28 \\
& Linoleic acid \\
Creatine monohydrate \\
Acetyl-L-carnitine \\
Inosine \\
Treonine \\
Glucosamine sulfate \\
Low-dose naltrexone \\
Transdermal histamine with caffeine \\
Hyperbaric oxygen therapy \\
Hippotherapy \\
Yoga \\
Manipulative and body-based practices & Massage therapy \\
Chinese acupuncture \\
Electroacupuncture \\
Progressive muscle relaxation therapy \\
Neural therapy \\
Naturopathic medicine \\
\hline
\end{tabular}

Adapted from Yadev et al. ${ }^{2}$ know about all the CAM therapies they are taking. Clinicians use these evidence-based guidelines to help guide their patients to effective and safe treatments.

\section{REFERENCES}

1. Complementary, Alternative, or Integrative Health: What's in a Name? Available at: http://nccam.nih.gov/health/ whatiscam. Accessed February 9, 2014.

2. Yadav V, Bever C Jr, Bowen J, et al. Summary of evidencebased guideline: complementary and alternative medicine in multiple sclerosis. Neurology 2014;82:1083-1092. 


\section{PATIENT PAGE}

Section Editors

David C. Spencer, MD

Steven Karceski, MD

Robert J. Fox, MD, FAAN

\section{About evidence-based guidelines}

WHAT ARE EVIDENCE-BASED GUIDELINES? Evidencebased guidelines are recommendations to clinicians about the diagnosis and clinical management of particular diseases. The best way to diagnose or treat a disease is often not clear. Studies of diagnostic tools or treatments may be in conflict. It is helpful to review all the studies and integrate them into clearly defined recommendations. This process helps clinicians choose the best diagnostic tools or treatments for diseases. Evidence-based guidelines examine the quality of diagnostic or treatment studies. They give clinicians a recommendation and rate the degree of confidence in that recommendation.

\section{HOW ARE EVIDENCE-BASED GUIDELINES} DEVELOPED? The American Academy of Neurology (AAN) established a strict process to develop evidencebased guidelines. The AAN identifies an important question and then selects a panel of unbiased experts to conduct the review. A medical research librarian then helps perform a comprehensive search of the medical literature. This allows researchers to identify articles of potential relevance to the question at hand. At least 2 researchers independently review and rate the quality of each article using an established classification system. This rating reflects how the trial was designed and conducted. For example, a clinical trial directly comparing 2 therapies would be considered higher quality than a report of a handful of patients who received just 1 therapy. The quality of studies is rated on a 4-point scale-from Class I, which is the highest quality, to Class IV, which is the lowest quality. In some situations, no recommendations can be made. This includes situations where no studies of a treatment are available, studies were of low quality, or studies yielded conflicting results. The panel then develops recommendations. These recommendations include statements such as "probably" and "possibly" to describe the degree of confidence regarding that recommendation. The panel's recommendations are then sent for comments to many outside groups, including neurologists with expertise in that area and patient advocacy groups. The final guideline is then published. This process of developing an evidence-based guideline is very detailed and purposeful, so it can sometimes take several years to complete.

WHAT DO CLINICIANS DO WITH EVIDENCEBASED GUIDELINES? Guidelines are distributed to health care professionals in a variety of ways. These methods include e-mail, printed mail, posting on the AAN's Web site, and publication in the AAN's official journal, Neurology ${ }^{\circledR}$. Patient advocacy groups often help spread the word about newly established guidelines. It is then up to each clinician to decide how to incorporate the guidelines into clinical care. The clinician may need to adapt the guidelines to fit individual patient situations. Although the guidelines are constructed with careful consideration and diligence, clinicians are not obligated to follow the guidelines.

ARE EVIDENCE-BASED GUIDELINES UPDATED? Evidence-based guidelines are updated from time to time, particularly when significant new information about the subject has been published. 


\section{PATIENT PAGE}

Section Editors

David C. Spencer, MD

Steven Karceski, MD
Robert J. Fox, MD, FAAN

\section{About multiple sclerosis}

WHAT IS MULTIPLE SCLEROSIS? Multiple sclerosis (MS) is a disease in which the immune system gets confused and attacks the brain, spinal cord, and optic nerve (the cable that connects the eyes to the brain). Symptoms of MS may include blurry vision, double vision, numbness, weakness, walking problems, and bladder and bowel problems. Basically, any body function that is controlled by the brain or spinal cord can be affected by MS. MS most commonly starts with episodes, which are called relapses. Typical relapses come on over several days to weeks and then slowly resolve over weeks or months. Recovery from relapses is not always complete and can leave behind permanent symptoms. The first symptoms of MS typically occur between 20 and 40 years of age, although MS can affect children and can sometimes first start in the elderly. We don't know what causes MS. A person's genes and some things in the environment may play a role in developing MS, but we don't know all the details.

HOW IS MS DIAGNOSED? MS is diagnosed through a combination of a typical history for MS, a neurologic examination suggesting MS, and exclusion of other potential conditions. MRI has become an important tool in the diagnosis of MS. MRI can both show typical lesions (or scars) of MS and exclude other possible conditions. In most cases, MS starts with intermittent relapses and is called "relapsingremitting MS" (RRMS). After 10-20 years, MS can change. The clinical relapses become uncommon and are instead replaced by gradual little-by-little progression of neurologic symptoms such as walking difficulties. This form of MS is called "secondary progressive MS" (SPMS). There is no abrupt change between RRMS and SPMS but rather a gradual transition. About $10 \%$ of patients with MS never have relapses and instead have only gradual, little-bylittle progression of neurologic symptoms from the onset of disease. This form of MS is called "primary progressive MS" (PPMS).

HOW IS MS TREATED? The goals of MS treatment are to stop episodes of brain inflammation, to prevent further inflammation, and to relieve the lasting neurologic symptoms caused by prior attacks. MS treatment is divided into 3 main categories.
Treating inflammation. Clinical relapses are caused by active inflammation affecting the brain, spinal cord, and optic nerve. This active inflammation is typically treated with a course of high-dose corticosteroids, such as IV methylprednisolone. Corticosteroids can help accelerate recovery from a clinical relapse and may reduce the amount of injury from MS. Corticosteroid treatment is sometimes used to treat active inflammation seen on MRI, even in the absence of clinical symptoms. Corticosteroid treatment is often done as an outpatient, but occasionally patients need to be hospitalized for this treatment.

Preventing inflammation. There are 10 therapies approved by the US Food and Drug Administration to treat MS. They all work by preventing inflammation. Different therapies work differently, have different side effects, and have different risks to the people taking them. The risks of therapies may be different for different individuals. The choice of therapy depends on the severity of the MS, personal tolerance for different potential side effects, and overall risks of side effects and complications. Monitoring the effect of therapy on MS disease activity includes assessment of the frequency and severity of relapses. Brain MRI has become an important tool to assess the adequacy of MS treatment. New or active lesions on MRI indicate suboptimal efficacy and may suggest the need to change treatments.

Treating symptoms. MS can cause many chronic symptoms. These symptoms include weakness; stiffness (called spasticity); pins-and-needles and other changes in sensation; walking difficulties; urinary urgency, frequency, and incontinence; constipation; depression and anxiety; and cognitive difficulties such as memory and concentration problems. For manyalthough not all—of these symptoms, there are treatments that can help. Treatments often include medications but can also include physical therapy, occupational therapy, assistive devices (i.e., canes, walkers), counseling, and changes in diet.

WHAT IS THE PROGNOSIS? If MS can be diagnosed early and effective treatment is implemented early in the disease course, patients typically have a very good long-term prognosis. Even if the initial 
treatment is suboptimally effective, prognosis can still be very good if therapy is changed to a more effective treatment. However, the later MS is diagnosed and the more damage MS causes before the inflammation is stopped, the harder it is to alleviate the symptoms. Currently, there are no effective treatments to slow the gradual course of progressive MS (either SPMS or PPMS). However, symptomtargeted treatments can be helpful in relieving symptoms and improving quality of life.
FOR MORE INFORMATION

AAN Patients and Caregivers site http://patients.aan.com/go/home

Multiple Sclerosis Association of America http://www.msassociation.org

Multiple Sclerosis Foundation http://www.msfocus.org

National Multiple Sclerosis Society http://www.nationalmssociety.org 


\section{Neurology}

\section{Complementary and alternative medicine in multiple sclerosis \\ Robert J. Fox \\ Neurology 2014;82;e103-e107 \\ DOI 10.1212/WNL.0000000000000307}

This information is current as of March 24, 2014

\section{Updated Information \& Services}

References

Subspecialty Collections

Permissions \& Licensing

Reprints including high resolution figures, can be found at: http://n.neurology.org/content/82/12/e103.full

This article cites 1 articles, 1 of which you can access for free at: http://n.neurology.org/content/82/12/e103.full\#ref-list-1

This article, along with others on similar topics, appears in the following collection(s):

All Demyelinating disease (CNS)

http://n.neurology.org/cgi/collection/all_demyelinating_disease_cns All Immunology

http://n.neurology.org/cgi/collection/all_immunology

Multiple sclerosis

http://n.neurology.org/cgi/collection/multiple_sclerosis

Information about reproducing this article in parts (figures,tables) or in its entirety can be found online at:

http://www.neurology.org/about/about_the_journal\#permissions

Information about ordering reprints can be found online:

http://n.neurology.org/subscribers/advertise

Neurology ${ }^{\circledR}$ is the official journal of the American Academy of Neurology. Published continuously since 1951, it is now a weekly with 48 issues per year. Copyright @ 2014 American Academy of Neurology. All rights reserved. Print ISSN: 0028-3878. Online ISSN: 1526-632X.

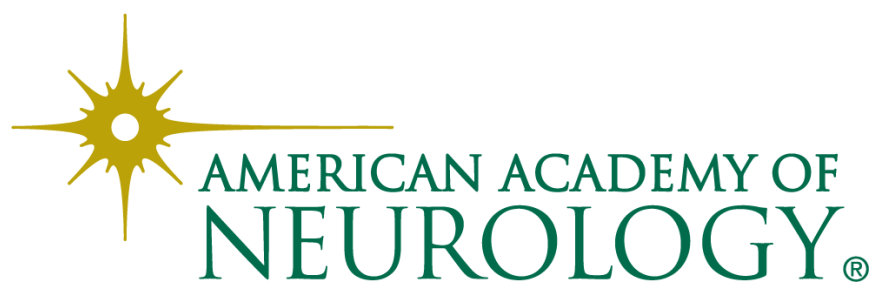

